\title{
The Economic and Climate Value of Flexibility in Green Energy Markets
}

\author{
Jan Abrell ${ }^{1}$ D $\cdot$ Sebastian Rausch ${ }^{1,2,3,4} \cdot$ Clemens Streitberger $^{5}$
}

Accepted: 2 September 2021 / Published online: 30 September 2021

(C) The Author(s) 2021

\begin{abstract}
This paper examines how enhanced flexibility across space, time, and a regulatory dimension affects the economic costs and $\mathrm{CO}_{2}$ emissions of integrating large shares of intermittent renewable energy from wind and solar. We develop a numerical model which resolves hourly dispatch and investment choices among heterogeneous energy technologies and natural resources in interconnected wholesale electricity markets, cross-country trade (spatial flexibility), energy storage (temporal flexibility), and tradable green quotas (regulatory flexibility). Taking the model to the data for the case of Europe's system of interconnected electricity markets, we find that the appropriate combination of flexibility can bring about substantial gains in economic efficiency, reduce costs (up to 13.8\%) and lower $\mathrm{CO}_{2}$ emissions (up to $51.2 \%$ ). Regulatory flexibility is necessary to realize most of the maximum possible benefits. We also find that gains from increased flexibility are unevenly distributed and that some countries incur welfare losses.
\end{abstract}

\section{Introduction}

The electricity sector is one of the most important areas for policies aimed at mitigating climate change (European 2011). Globally, about $40 \%$ of $\mathrm{CO}_{2}$ emissions from fuel combustion can be attributed to electricity and heat production (International 2018). The demand for electricity is expected to grow substantially in the coming decades due to population

Jan Abrell

jan.abrell@zew.de

Sebastian Rausch

sebastian.rausch@zew.de

Clemens Streitberger

c.streitberger@gmail.com

1 ZEW Leibniz Centre for European Economic Research, Mannheim, Germany

2 Department of Economics, Heidelberg University, Heidelberg, Germany

3 Centre for Energy Policy and Economics at ETH Zurich, Zurich, Switzerland

4 Joint Program on the Science and Policy of Global Change at Massachusetts Institute of Technology, Cambridge, USA

5 Department of Management, Technology and Economics, ETH Zurich, Switzerland 
and economic growth and the increasing electrification (Williams et al. 2012) in emissionsintensive sectors such as transportation. In addition, developing environmentally-friendly hydrogen-based substitutes for fossil fuels based on power-to-X technologies, which could also help to decarbonize industry and offer alternative low-carbon pathways for the transport sector, require green electricity. Renewable energy (RE) from wind and solar is at the core of a transformation towards green electricity (Rogelj et al. 2018).

Due to the importance of RE for the decarbonization of the economy, extensive renewable support schemes have been implemented all over the world. In its Renewable Energy Directive (European 2009) the European Union implemented a target of 20\% of total energy demand to be covered by RE sources. Subsequently, the target was increased to $32 \%$ for the year 2030 (European 2018) with the possible further increase after a review in 2023. RE support is, however, not addressed with a uniform regulation at the European level. Each member state is responsible for implementing the target, which leads to various, country-specific RE support schemes mostly in form of RE premiums providing a fixed income for energy produced by RE.

Carbon-free energy from such sources is highly intermittent and the quality and distribution of wind and solar resources differ largely across time and space. This underlying resource heterogeneity has been found to create heterogeneous market and environmental values of $1 \mathrm{MWh}$ produced from wind compared to $1 \mathrm{MWh}$ from solar (Fell and Linn 2013; Wibulpolprasert 2016; Abrell et al. 2019; Abrell et al. 2019). A cost-effective integration of large amounts of intermittent RE thus has to create sufficient flexibility in the market system to exploit these heterogeneous valuations.

This paper examines how enhancing the flexibility along key dimensions of future electricity markets affects the economic costs and $\mathrm{CO}_{2}$ emissions of integrating large shares of highly volatile renewable energy. We develop a model of interconnected electricity markets which captures the heterogeneity in time, technology, natural resource availability, withinmarket (supply and investment) decisions, and cross-market electricity trade. We take the model to the data, using the case of Europe's system of interconnected electricity markets, and incorporate important model and empirical detail for studying the large-scale integration of RE in (future) electricity markets. ${ }^{1}$ Our empirical-quantitative framework resolves wholesale electricity markets at the hourly level to account for seasonal and intra-day variation of RE sources and demand, country-specific potentials for RE resources, non-renewable production capacities, and capacities for electricity trade across time (energy storage) and across space (as bound by available cross-border transmission infrastructure). The temporal and spatial resolution of our empirical-quantitative framework enables us to analyze the economic value of increased temporal flexibility through energy storage and increased spatial flexibility through cross-market trade. Another important flexibility mechanism pertains to the type of RE support policy: we investigate how the economic cost of RE integration depends on whether the EU-wide renewable targets for electricity are implemented by uncoordinated policy measures at the national level (national RE quotas) or through a system of tradable RE quotas at the European level which involves implicit coordination and more flexibility through a market-based regulatory approach.

\footnotetext{
1 Related literature has emphasized the need for including the main building blocks of a future system in an analysis, such as storage investments (Zerrahn and Schill 2017; Schill and Zerrahn 2018; Schill 2014; Sinn 2017; Abrell et al. 2019), cross-border trade (Abrell and Rausch 2016), and possible emissions impacts (Linn and Shih 2016; Carson and Novan 2013; Helm and Mier 2018).
} 


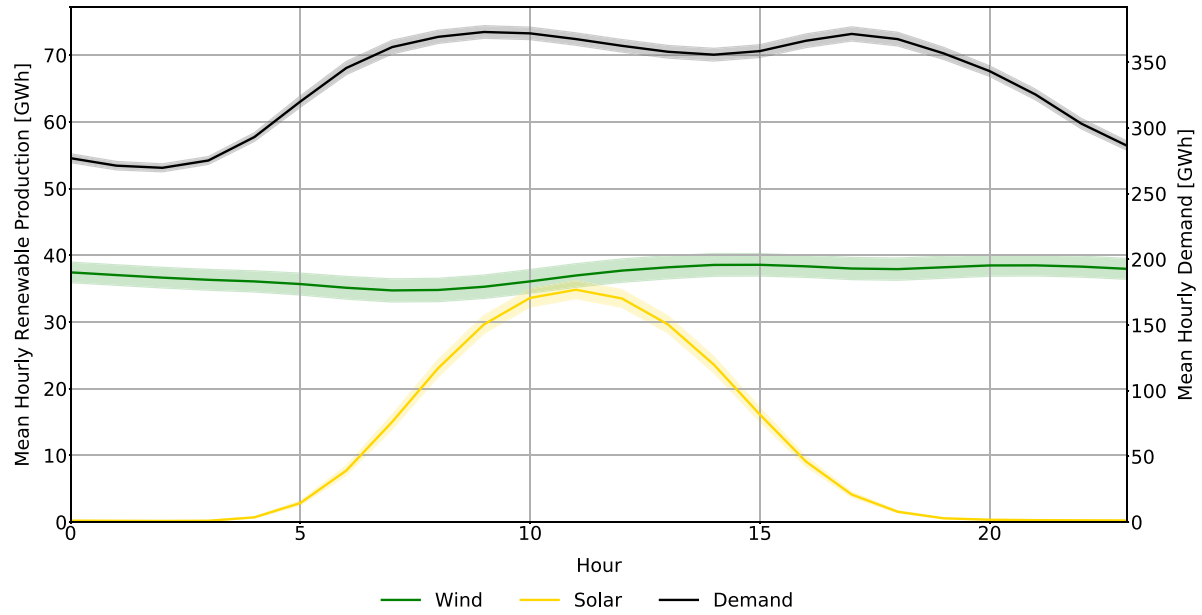

Fig. 1 Hourly profiles of electricity demand and electricity generation from wind and solar over an average day in Europe. Averages for each hour of the day in 2017. Shaded areas indicate 95 percent CI. Sources: (ENTSO-E 2017) and (ENTSO-E 2017)

Figure 1 illustrates the potential of enhancing "temporal flexibility": neither production from wind, nor solar generation follows demand closely over the course of a typical day; even though a combined use of both technologies will fare better, there remains the need to shift solar production from daytime to nighttime and wind energy from off-peak to peak hours. Trade between countries enables a pooling of natural resources and different availability profiles for RE, conventional generation capacities, and also demand over larger distances (von der Fehr and Sandsbraten , 1997; Antweiler , 2016). We refer to this as "spatial flexibility". Figure 2 visualizes the time-correlations and thus geographical variations in demand and availability of RE generation in Europe. We see high correlations between demand patterns and solar generation patterns in Fig. 2a and d, already indicating that the potential of solar energy to supply flexibility to a European system with largely similar demand structures in all countries is limited. The correlations between wind and solar and wind and wind in Fig. $2 \mathrm{f}$ and e are much lower. A combination of both technologies and increased capacities for trade between distant regions with differing wind patterns may hence have the potential to significantly mitigate the supply-demand mismatch due to high shares of RE. At the same time, however, reaping benefits from spatial flexibility also critically depends on the natural resource quality of the various regions and their investment cost. Figure 3 takes a look at the heterogeneous RE resource quality among European countries, providing a scatter plot of the marginal investment costs of expanding RE generation against the maximum RE generation potential. The large variation in resource quality points to potential gains from trade through enhancing spatial flexibility. Importantly, the market and system perspective of our model allows us to study the interaction between different channels of flexibility. Our analysis can thus shed light on which combination of flexibility is most effective in lowering economic costs and $\mathrm{CO}_{2}$ emissions through a large-scale integration of RE. 


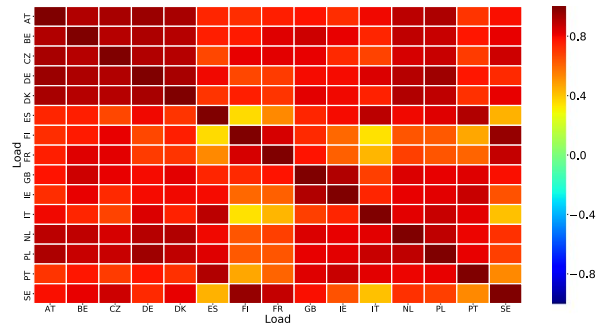

(a) Demand with demand

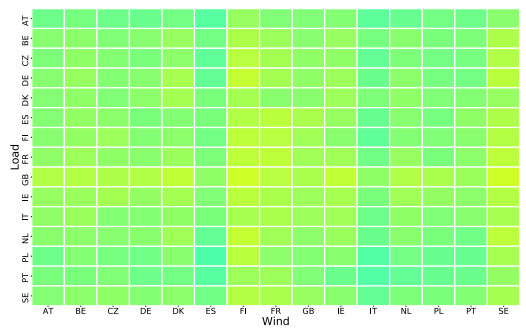

(c) Wind generation with demand

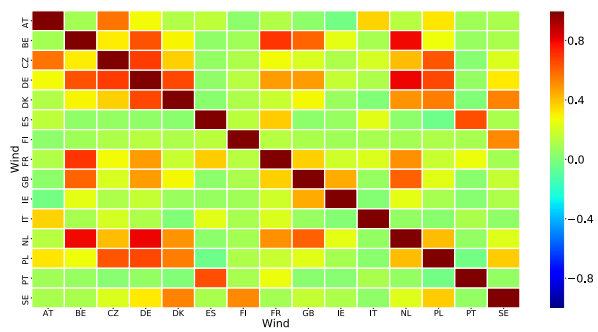

(e) Wind generation with wind generation

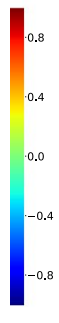

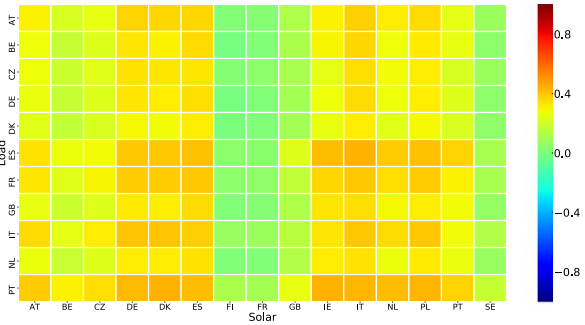

(b) Solar generation with demand

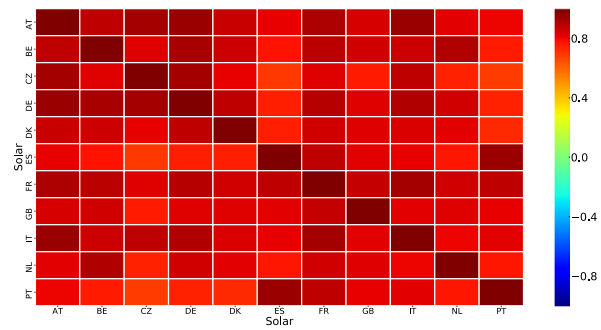

(d) Solar generation with solar generation

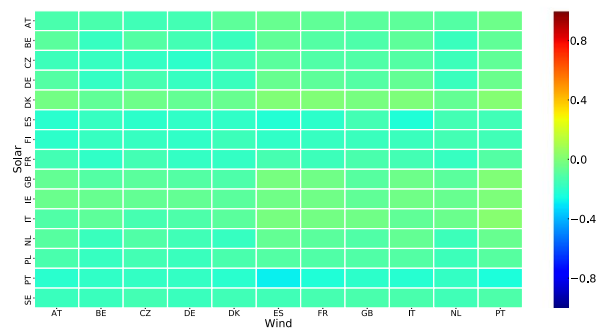

(f) Wind generation with solar generation.

Fig. 2 Heat maps of cross-country hourly correlation coefficients for Europe. Own calculations. In a, b, c: hourly electricity demand in 2017 (Source: ENTSO-E 2017). In b, d, f: hourly generation from PV generation in 2017 (Source: ENTSO-E 2017). In c, e, f: hourly generation from wind power in 2017 (Source: ENTSO-E 2017). Country codes are defined in Table 6

We measure the economic value of flexibility by the induced net economic benefits related to changes in the market surplus. ${ }^{2}$ To measure the net benefits in each region, we account for the gains from cross-market trade and energy storage, congestion rents on scarce cross-border transmission capacity, income from trade in RE permits, and generation and investment cost at the regional level. Importantly, this enables us to not only examine the value or economic benefits of added flexibility at the aggregate (system or EU level) but also to explore the distribution of gains and losses at the country level. ${ }^{3}$

\footnotetext{
2 As we consider electricity demand as exogenously given and fixed, maximizing the market surplus is equivalent to maximizing producer surplus or minimizing (generation and investment) cost.

${ }^{3}$ Our analysis focuses on the potential maximum benefits from adding flexibility to a system of interconnected electricity markets; it ignores, however, the costs associated with building up the energy storage and cross-border trade capacities to create flexibility. A full cost-benefit analysis is beyond the scope of this paper, and there would be major problems regarding the availability and measurement of cost data and the
} 


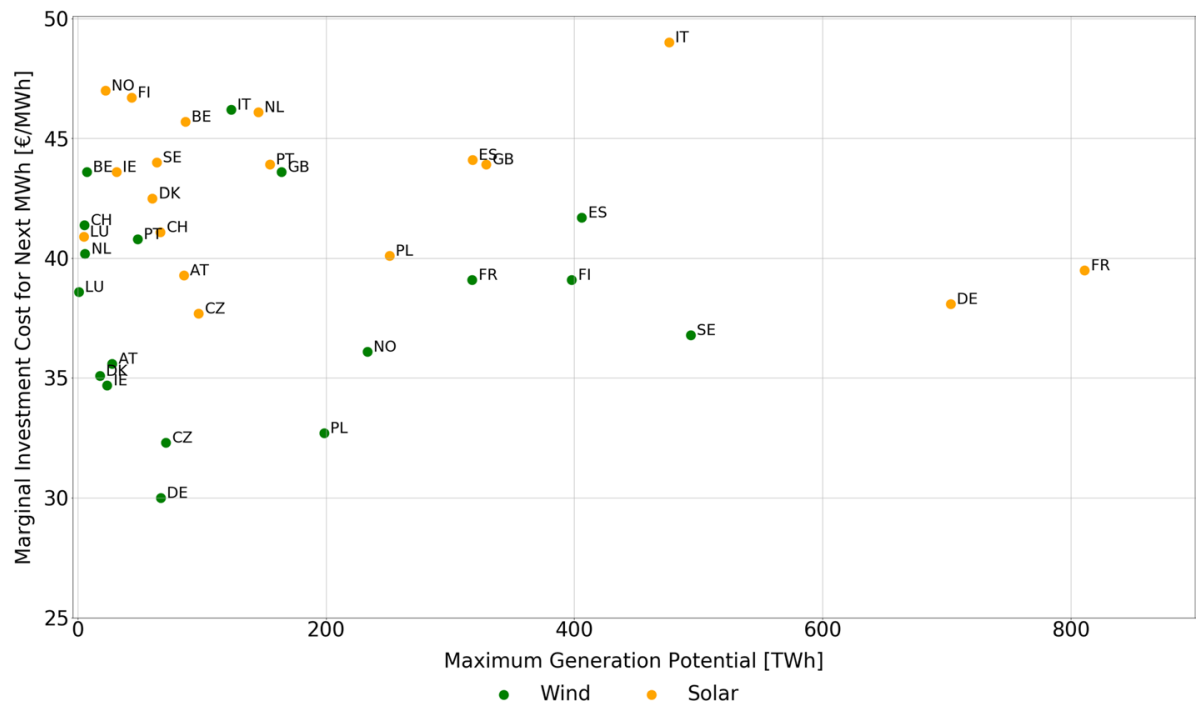

Fig. 3 RE resource quality by European country: marginal investment costs of expanding RE generation and maximum RE generation potential. Maximum generation potential refers to maximum attainable quantity of generation if all available and suitable locations are used (Tröndle et al. 2019, 2019). Marginal investment cost for an incremental MWh of generation added beyond the level of installed capacity in 2017 (see Sect. 3 for detail). Country codes are defined in Table 6

Our main findings are as follows. First, the potential economic benefits from adding flexibility across space and time are considerable. Relative to a case which reflects existing storage and transmission capacities, allowing for "unlimited" flexibility along these two dimensions (i.e., relaxing the constraints for energy storage and cross-border electricity transmission) yields cost savings of $8.6 \%$ for integrating wind and solar when they account for very high shares of electricity generation in Europe. ${ }^{4}$ We find that regulatory flexibility is key to further reduce the costs of renewable energy integration. Switching from national RE quotas to a system of EU-wide tradable quota increases the cost savings to $13.8 \%$. At the same time, regulatory flexibility on its own has a limited value (cost savings of $2.5 \%$ ) as physical obstacles in the form of restricted energy storage and transmission capacities prevent substantial savings through reduced curtailment of RE generation. The value of flexibility through a regulatory channel is particularly important in view of the fact that adding energy storage and transmission capacity involves significant costs that are likely to far exceed the administrative costs associated with regulation.

\footnotetext{
Footnote 3 (continued)

uncertainties associated with these data, which would have to be overcome to produce such a cost-benefit analysis. We believe that our quantitative assessment of the benefits side is a useful step in this direction.

${ }^{4}$ Specifically, we conduct our analysis for a situation where wind and solar account for $70 \%$ of total generation. Although higher targets would lead to similar qualitative findings, we deliberately refrain from such an analysis because it raises a host of other important issues beyond the scope of this paper which are related to the design of future electricity markets and would go substantially beyond the current setup of a predominantly "energy-only" market which can be represented in our model (e.g., issues of capacity and flexibility remuneration, resource adequacy, and marginal vs. average cost pricing).
} 
Second, the combination of several flexibility channels is always better than one but the benefits are not simply additive. We find that combining flexibility across space and the regulatory dimension reaps most of the maximum potential gains. The value of flexibility across time (through energy storage) alone is quite limited, in particular when storage losses are not negligible. Given a large and geographically diverse European electricity market, our analysis suggests that geographical flexibility is probably better suited to equalize marginal investment and generation costs across the region.

Third, the new renewable technologies, wind and solar, interact differently with the flexibility channels. Regardless of geographical position, solar energy is highly concentrated around noon and null during the night. Hence, high shares of solar energy are only favorable when storage capacity is high. Wind generation patterns are more diverse in different parts of Europe and thus wind has an advantage over solar when cross-border transmission capacity is relaxed, and especially when a flexible regulatory framework enables an efficient use of geographical advantages for RE resource-rich countries and for resource-poor countries through the purchase of RE permits.

Fourth, the climate value (i.e., $\mathrm{CO}_{2}$ emissions effect) of integrating a given share of intermittent renewables varies considerably, depending on how flexible the market system is. For our central case of $70 \%$ of electricity generation from wind and solar, the $\mathrm{CO}_{2}$ emissions impact ranges from $-51.2 \%$ to $+6.2 \%$ when compared to the case which reflects existing storage and transmission capacities. ${ }^{5}$ Emissions actually increase when only regulatory flexibility is added. The intuition is that countries with high marginal investment cost for RE will buy tradable green permits from other countries and increase production from cheap but dirty fossil capacity compared to the case when RE targets in each country have to be met separately. Increased storage capacity favors base load producers in each country and disadvantages peak load producers. As a consequence, there is a shift in production to each country's low-cost technologies. Since many European countries have coal or nuclear energy as cheap base load technologies, the impact on emissions from storage may either be positive or negative in a given country. The effect of unconstrained trade capacity is different in that it creates a single supply curve for the whole model region and in such a scenario the absolutely cheapest technologies are dispatched first rather than the relatively cheapest production capacity in each country. This favors nuclear and hydro installations over coal and causes larger emissions reductions compared to the scenarios with unconstrained storage. Overall, our analysis clearly suggests that the decarbonization of the energy sector should not only be based on pushing wind and solar energy into the domestic market by increasing their cost competitiveness compared to fossil-based technologies, but that an effective integration of intermittent RE sources through additional market flexibility is also crucial.

Finally, we find that the gains from increased flexibility are unevenly distributed, with some countries being even worse off. This is mainly due to the diverse RE potentials and existing conventional capacity mixes which translate into different potentials for cost savings. This suggests that the large-scale integration of intermittent renewables in a highly integrated transnational electricity system may require compensating measures at the European level to overcome political hurdles. While it is beyond the scope of this paper to offer an analysis of this question, it is nevertheless important to be aware that designing a more

\footnotetext{
${ }^{5}$ Going from the current levels of wind and solar to a future system of $70 \%$, reduces the $\mathrm{CO}_{2}$ emissions in the European power sector (from a level of $676.3 \mathrm{Mt}$ ) by $70.4 \%$ to $86.4 \%$.
} 
efficient system on an aggregated level does not necessarily guarantee that there are only (country) winners.

To the best of our knowledge, this paper is the first to combine the three flexibility channels available for the market integration of RE generation in a single framework. It is connected to several strands of the literature which are mostly focusing on one flexibility channel. First, there is an ongoing debate on the necessary investments into storage to accommodate new RE generation. Sinn (2017) argues that very high shares of RE generation require prohibitively high investments into storage capacity because otherwise large percentages of possible RE generation would have to be curtailed. In contrast to that, Zerrahn et al. (2018) show that already allowing for a small amount of curtailment leads to a large saving in investment cost for storage facilities. A second strand of the literature concentrates on the interaction of storage capacity with existing conventional and new renewable technologies. Crampes and Moreaux (2010) analyze the interaction of pumped hydro storage with conventional fossil generation technologies and derive how to optimally use the technologies together without considering investment into new RE capacity. Linn and Shih (2016) employ a numerical model of the Texas ERCOT region to analyze how new storage capacities interact with current electricity systems featuring emissions intensive generation from coal, cleaner electricity production from gas, and zero emissions electricity from wind and solar energy. They lay a focus on the resulting total carbon emissions. Similarly, Carson and Novan (2013) investigate emissions effects with data from the ERCOT region using a theoretical model and empirical methods and in addition they study the effects of new storage capacity on peak and off-peak producers. The papers in these two strands of the literature analyze temporal flexibility through storage and we contribute by adding the interaction with regulatory and spatial flexibility.

Third, there is an emerging literature on regulatory design in electricity markets with storage. Helm and Mier (2018) focus on the emissions impacts of subsidies for storage. Abrell et al. (2019) show that costly curtailment of RE generation can be reduced by tailoring the design of the regulatory regime to achieve a better matching between renewable supply and demand patterns. Whereas these papers analyze increasing temporal and also regulatory flexibility, we contribute by extending the range of the analysis by adding spatial flexibility by means of electricity trade.

Fourth, spatial flexibility of electricity generation is discussed in the literature about international electricity trade. von der Fehr and Sandsbraten (1997) analyze the impact of increasing electricity trade in Nordic countries. Antweiler (2016) develops a theory of international trade in a homogeneous commodity, electricity, and shows how two-way trade can emerge because of temporal differences in load patterns. Abrell and Rausch (2016) investigate a multi-sector general equilibrium model with a detailed representation of the European electricity sector to assess the impact of higher shares of renewables on gains from trade and $\mathrm{CO}_{2}$ emissions. This strand of the literature analyzes spatial flexibility of electricity generation but does not assess the effect of temporal flexibility by means of storage.

Fifth, we also make a connection to a growing literature investigating the consequences of the fundamental heterogeneity of RE technologies with respect to availability patterns. Abrell et al. (2019) point out that the environmental value and market value of different renewables may vary and suggest that differentiating subsidies by technology might improve the environmental impact of RE policies, while Fell and Linn (2013) and Wibulpolprasert (2016) analyze how heterogeneity in renewable resource availability affects the cost-effectiveness of various abatement policies. Abrell et al. (2019) use an empirical approach to conduct an ex-post evaluation of market values and environmental values of 
RE sources. These studies focus on lessons for regulatory design emerging from the heterogeneity of renewable production profiles. In this way, they introduce regulatory flexibility. However, these papers do not assess the flexibility of the regulatory regime across regions and its relation to international trade and storage facilities.

The remainder of this paper proceeds as follows. Section 2 presents the conceptual model. Section 3 describes the data and our empirical strategy to bring the model to the data. Section 4 presents and discusses the main results from our computational analyses of the economic and environmental value of temporal, spatial, and regulatory flexibility in the European electricity market. Section 5 concludes.

\section{Model}

\subsection{Overview}

We base our empirical-quantitative analysis on a numerical partial equilibrium model of interconnected electricity markets. We formulate the model as a social planner's problem to minimize total cost while reaching an ambitious target for the share of renewable energy in overall electricity production. The model features an hourly time resolution for the 8760 hours of a year to capture seasonal changes in time-dependent demand and availability of RE sources, several model regions which are connected by limited transfer capacities for trade, investment in new RE capacity, curtailment of RE production if necessary to ensure system stability, and a generic storage technology. The net transfer capacities for trade and storage capacities are treated as given exogenously, i.e. we abstract from investment decisions in grid and storage infrastructure and the associated cost. We apply our conceptual framework to the context of the European electricity market by calibrating the model to 2017 conditions of 18 European countries. Capturing country-specific potentials for RE resources and heterogeneous conventional generation capacities enables us to explore the interactions of electricity systems with a wide range of generation technology mixes under several policy scenarios. Our framework permits examining the $\mathrm{CO}_{2}$ emissions implications from adding flexibility to the European electricity sector.

\subsection{Conceptual Framework}

THE SOCIAL PLANNER'S PROBLEM. — We adopt a social planner's approach according to which sufficient electricity has to be supplied to meet total exogenous, price-inelastic demand $^{6}$ at lowest cost $\mathcal{C}^{\text {tot }}$ subject to fulfilling an exogenously given target for generation from renewable sources and a number of constraints $\mathcal{B}$, which reflect specific properties of the electricity market. Formally, this may be written as:

$$
\min _{\mathbf{Q}} \mathcal{C}^{\text {tot }}(\mathbf{Q}) \quad \text { s. t. } \quad \mathcal{B}(\mathbf{Q}),
$$

where the choice variables are given by a vector $\mathbf{Q}$ comprising the quantity variables of the model, conventional hourly generation $X$, yearly renewable generation $G$, curtailment $C$, storage level $S$, injection into storage $J$, release from storage $R$, and trade $T$.

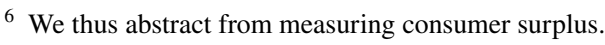


Total cost is given by the sum of generation cost for electricity, $\mathcal{C}^{\text {gen }}$, and investment cost for new renewable capacity, $\mathcal{C}^{\text {inv }}$ :

$$
\mathcal{C}^{\text {tot }}=\mathcal{C}^{\text {gen }}+\mathcal{C}^{\text {inv }}
$$

The model features generation from conventional, dispatchable technologies which we denote by $i \in \mathcal{I}$, intermittent generation from new renewable sources $r \in \mathcal{R}$ and storage technologies $s \in \mathcal{S}$. Time periods are denoted by $t \in \mathcal{T}$ and the regions constituting the submarkets are identified by $c \in \mathcal{C}$.

GENERATION AND INVESTMENT.— Generation from conventional energy sources, $X_{i c t}$, is dispatchable and needs to be chosen for each time period such that it cannot exceed the available installed capacity:

$$
\alpha_{i c t} \bar{k}_{i c} \geq X_{i c t}, \quad \forall i, c, t,
$$

where $\bar{k}_{i c}$ denotes the installed capacity of technology $i$ in region $c$ and $\alpha_{i c t}$ is a factor describing the percentage of actually available production capacity due to factors such as maintenance of conventional power plants.

Generation from new renewable sources (wind and solar), $G_{r c}$, is intermittent, i.e. it depends on the availability of the natural resource and is hence non dispatchable. The social planner chooses to invest into a capacity which produces a total quantity of $G_{r c}$ per year on top of already existing capacity equivalent of generating $\bar{r}_{r c}^{\text {tot }}$ per year, the sum of which cannot exceed the technically feasible potential, $\pi_{r c}$, for each technology $r$ in region $c$ :

$$
\pi_{r c} \geq \bar{r}_{r c}^{\mathrm{tot}}+G_{r c}, \quad \forall r, c .
$$

CURTAILMENT. — Hourly generation from RE sources is determined by an exogenous factor, $\alpha_{r c t}$, which takes into account daily and seasonal changes in resource availability. The planner can also decide to discard part of the RE generation to ensure net stability at times when RE generation would be larger than demand. This curtailment, $C_{r c t}$, cannot exceed total RE generation at any given time:

$$
\alpha_{r c t}\left(\bar{r}_{r c}^{\mathrm{tot}}+G_{r c}\right) \geq C_{r c t}, \quad \forall r, c, t .
$$

TRADE. — The model permits electricity trade between regions. The variable $T_{c c^{\prime} t}$ indicates that electricity was traded from region $c$ to region $c^{\prime}$ at time period $t$. At any time, trade volume between regions cannot exceed the given net transfer capacity, $v_{c c^{\prime} t}$ :

$$
v_{c c^{\prime} t} \geq T_{c c^{\prime} t}, \quad \forall c, c^{\prime}, t \quad \text { and } \quad c \neq c^{\prime} .
$$

ELECTRICITY STORAGE. — The possibility to store electrical energy is provided by storage technologies which are described by a capacity to inject energy into the storage, $\bar{k}_{s c}^{J}$, a capacity to store a certain amount of energy, $\bar{k}_{s c}^{S}$, and a capacity to release energy from storage, $\bar{k}_{s c}^{R}$. The associated quantity variables $J_{s c t}, S_{s c t}$, and $R_{s c t}$ are bounded by these capacities at all times $t$ :

$$
\begin{aligned}
& \bar{k}_{s c}^{J} \geq J_{s c t}, \quad \forall s, c, t \\
& \bar{k}_{s c}^{S} \geq S_{s c t}, \quad \forall s, c, t
\end{aligned}
$$




$$
\bar{k}_{s c}^{R} \geq R_{s c t}, \quad \forall s, c, t
$$

In addition to these constraints, time consistency between periods needs to be ensured. We achieve this by introducing a law of motion for storage which states that the storage level, $S_{s c t}$ at time $t$ depends on the storage level at time $t-1$, injection and release and natural water inflows $\varphi_{\text {sct }}$ if the storage technology is represented by hydro reservoirs. Formally, this reads as:

$$
S_{s c(t-1)}+\eta_{s c} J_{s c t}-R_{s c t}+\varphi_{s c t}=S_{s c t}, \quad \forall s, c, t,
$$

where $\eta_{s c}$ denotes the round-trip efficiency of the storage technology and thus captures energy losses due to the storage cycle.

RENEWABLE ENERGY POLICY. - The social planner defines a goal for the quantity of renewable energy which can be (a) region-specific or (b) encompass all modeled regions:

$$
\begin{gathered}
\sum_{r}\left(\bar{r}_{r, c}^{\mathrm{tot}}+G_{r, c}-\sum_{t} C_{r c t}\right)=\tau_{c}, \quad \forall c \\
\sum_{r, c}\left(\bar{r}_{r, c}^{\mathrm{tot}}+G_{r, c}-\sum_{t} C_{r c t}\right)=\tau,
\end{gathered}
$$

where $\tau$ is the target for generation from RE sources.

MARKET CLEARING. — Electricity markets need to clear at all times in order to avoid a blackout, that is generation from all technologies, injection into storage, net trade, and curtailment must equal hourly demand $\bar{d}_{c t}$ in every region $c$ and every period $t$ :

$$
\begin{aligned}
& \sum_{i} X_{i c t}+\sum_{s}\left(R_{s c t}-J_{s c t}\right)+ \\
& \sum_{c^{\prime}}\left[\left(1-\lambda_{c^{\prime} c}\right) T_{c^{\prime} c t}-T_{c c^{\prime} t}\right]+ \\
& \sum_{r}\left[\alpha_{r c t}\left(\bar{r}_{r c}^{\mathrm{tot}}+G_{r c}\right)-C_{r c t}\right]=\bar{d}_{c t}, \quad \forall c, t,
\end{aligned}
$$

where $\lambda_{c^{\prime} c}$ denotes the transmission loss from region $c^{\prime}$ to $c$.

\subsection{Measuring Economic Benefits}

We measure economic benefits by sectoral surplus $W_{c}$ for each region $c \in \mathcal{C}$, which is given by the sum of gains of trade $\Gamma$, storage profits $\Phi$, congestion rents from the scarcity of transmission capacity $\Xi$, and income from green permit trade $\Pi$ less total $\operatorname{cost} \mathcal{C}^{\text {tot: }}$

$$
W_{c}=\Gamma_{c}+\Phi_{c}+\Xi_{c}+\Pi_{c}-\mathcal{C}^{\text {tot }}, \quad \forall c .
$$

Total cost is defined according to (2) as the sum of generation cost and investment cost defined in (18) and (19), respectively. 
The gains from trade are defined as export value minus import value: ${ }^{7}$

$$
\Gamma_{c}=\sum_{c^{\prime}, t} P_{c t} T_{c c^{\prime} t}-\sum_{c^{\prime}, t} P_{c t}\left(1-\lambda_{c^{\prime} c}\right) T_{c^{\prime} c t}, \quad \forall c .
$$

Storage profits are evaluated as the arbitrage of the storage operator from the price differences between times when stored electricity is released and when cheap electricity is added to the storage:

$$
\Phi_{c}=\sum_{s, t} P_{c t}\left(R_{s c t}-J_{s c t}\right), \quad \forall c
$$

Income from permit trade is defined as the difference between the value of the green permits obtained from actual domestic green production and the value of the permits that each country needs to hold according to the quota policy. By design, this difference is zero for the scenarios where permit trade is not possible:

$$
\Pi_{c}=\sigma\left[\sum_{r}\left(\bar{r}^{\mathrm{tot}}+G_{r c}-\sum_{t} C_{r c t}\right)-\tau_{c}\right], \quad \forall c,
$$

where $\sigma$ is the green permit price given by the shadow value of the policy constraint given in Eq. (11b).

Quantifying congestion rents $\Xi_{c}$ is difficult because it is not a priori clear (and in light of lacking empirical evidence) how they are split between the transmission operators in neighboring countries and bilateral agreements may differ. We adopt an approach where the congestion rents from trade are split equally between both countries and define $\Xi_{c}$ for a region $c \in \mathcal{C}$ as:

$$
\Xi_{c}=0.5 \cdot \sum_{c^{\prime}, t}\left(\xi_{c c^{\prime} t} T_{c c^{\prime} t}+\xi_{c^{\prime} c t} T_{c^{\prime} c t}\right), \quad \forall c
$$

where $\xi_{c^{\prime} c t}$ is the shadow value of the transmission constraint given in (6).

\section{Data and Empirical Strategy}

For the empirical specification of our model, we choose the year 2017 as our base year and collect all the relevant electricity market data for this year. The model features an hourly time resolution and to capture the seasonal variations in the demand and RE generation cycles we model all the 8760 hours of the year, which means that the set $\mathcal{T}$ of time periods is $\left\{t_{1}, \ldots, t_{8760}\right\}$. The model covers 18 European countries and 13 electricity generation and storage technologies which are listed in Table 2. For each of these countries and

\footnotetext{
7 We do not find empirical evidence which side of the market is paying for transmission losses. We thus assume, that the costs for imports are based on the imported quantity net of incurred transmission losses. We tested alternative assumptions and the distribution of regional gains and losses is not much affected by how the transmission losses are assigned.
} 
Table 1 Data sources and associations with model parameters

\begin{tabular}{ll}
\hline Model parameters & Data sources \\
\hline Conventional and storage capacities $\bar{k}_{i c}, \bar{k}_{s c}^{J}, \bar{k}_{s c}^{S}, \bar{k}_{s c}^{R}$ & ENTSO-E (2017) \\
Generation data for $\alpha_{i c t}, \alpha_{r c t}$, and $\bar{r}_{r c}^{\text {tot }}$ & ENTSO-E (2017) \\
Heat efficiencies $\eta_{i c}$, variable O\&M cost $c_{i c}^{\text {O \& M }}$ & Nuclear Energy Agency, International Energy \\
& Agency and OECD (2015) \\
Fuel cost $c_{i c}^{\mathrm{f}}$ & International (2019) \\
Renewable energy potentials $\pi_{r c}$ & Tröndle et al. (2019, 2019) \\
Renewable investment cost per MW & Kost et al. (2018) \\
Storage efficiency $\eta_{s c}$ & Egerer et al. (2014), Newbery (2016) \\
Demand $\bar{d}_{c t}$ & ENTSO-E (2017) \\
Net transfer capacities $v_{c c^{\prime} t}$ & ACER (2018), ENTSO-E (2018) \\
\hline
\end{tabular}

Table 2 Regions and technologies covered by the model

\begin{tabular}{ll}
\hline Regions $c \in \mathcal{C}$ & Austria, Belgium, Czech Republic, \\
& Denmark, Finland, France, Germany, \\
& Ireland, Italy, Luxembourg, \\
& Netherlands, Norway, Poland, \\
& Portugal, Spain, Sweden, \\
& Switzerland, United Kingdom \\
& Hard Coal $^{\mathrm{a}}$, Lignite $^{\mathrm{a}}$, Nuclear $^{\mathrm{a}}$, \\
Technologies & Other $^{\mathrm{a}}$, Biomass $^{\mathrm{b}}$, Reservoir $^{\mathrm{b}}$, \\
& Run-of-River $^{\mathrm{b}}$, Wind Onshore $^{\mathrm{c}}$, \\
& Wind Offshore $^{\mathrm{c}}$, Solar $^{\mathrm{c}, \mathrm{d}}$, Storage \\
\hline
\end{tabular}

${ }^{\mathrm{a} C o n v e n t i o n a l ~ t e c h n o l o g i e s, ~}{ }^{\mathrm{b}}$ renewable conventional technologies, ${ }^{\mathrm{c}}$ new renewable technologies, and ${ }^{\mathrm{d}}$ solar refers to rooftop solar

technologies we need to specify the relevant model parameters. The data sources and the parameters associated to them are summarized in Table $1 .{ }^{8}$

\subsection{Capacities and Marginal Cost for Conventional Generation}

The capacities for conventional technologies and storage, $\bar{k}_{i c}, \bar{k}_{s c}^{J}, \bar{k}_{s c}^{S}, \bar{k}_{s c}^{R}$ are taken from the database of the European Network of Transmission System Operators (ENTSO-E 2017). For the dispatchable fuel-based technologies (Hard coal, Lignite, Gas, Oil, Other) the reported capacities can be treated as net generation capacities and we choose the availability factor $\alpha_{i c t}=1$, accordingly. The effective net generation capacity of hydro power (Run-of-River, Reservoir) depends on complex and geographically diverse hydrological processes. We capture the seasonal production patterns of Run-of-River plants by treating their generation as exogenous and use the generation data from ENTSO-E for the base year

\footnotetext{
8 The model described in Sect. 2 is a "quadratic program" with a quadratic objective function and linear constraints. We formulate the model equations in the General Algebraic Modeling System (GAMS) and use the GAMS/CPLEX solver to solve the quadratic program.
} 
(ENTSO-E 2017) reflecting the fact that Run-of-River as a low marginal cost technology is dispatched whenever available. For Reservoirs, we obtain weekly reservoir levels from the ENTSO-E database (ENTSO-E 2017) and calculate natural inflows $\varphi_{s t}$ on this basis. ${ }^{9}$ For generation from biomass and nuclear we choose the availability factors such that their output is in line with actually observed generation rather than their considerably higher theoretical maximum output.

Conventional producers incur marginal generation cost, $\partial \mathcal{C}^{\text {gen }} / \partial X_{i c t}$, when generating electricity. We specify the marginal generation cost function as the sum of fuel cost and variable operation and maintenance $(\mathrm{O} \& \mathrm{M})$ cost:

$$
\frac{\partial \mathcal{C}^{\mathrm{gen}}}{\partial X_{i c t}}=\frac{c_{i c}^{\mathrm{f}}}{\eta_{i c}}+c_{i c}^{\mathrm{O} \& \mathrm{M}},
$$

where the heat efficiencies, $\eta_{i c}$, are taken from the IEA (2015). and the fuel cost, $c_{i c}^{\mathrm{f}}$, is taken from IEA (2019) for the countries where data is available. For technologies such as hydro power the heat efficiency is set to 1 . For the remaining countries, the missing data was filled with cost information from neighboring countries (see Table 7 for details). We take the same approach for the variable O\&M costs, $c_{i c}^{\mathrm{O} \& \mathrm{M}}$. Where available, data is taken from IEA 2015 and the remaining values are filled as given in Table $8 .^{10}$

\subsection{Resource Potentials and Investment Costs for Wind and Solar}

Yearly generation from existing new renewable capacity, $\bar{r}^{\text {tot }}$, is taken from ENTSO-E (2017) for the countries where data is available. This information is used to calibrate the hourly availability factors for new renewables, $\alpha_{r c t}$, as the share of each hour in total generation. In this way, $\alpha_{r c t}$ captures both the intra-day and seasonal variations in resource availability for new RE. For countries with missing data, we fill the gaps with data from neighboring countries as given in Table 9.

Producers of wind and solar energy face near zero marginal generation cost and the dominating cost factor is marginal investment cost $\partial \mathcal{C}^{\text {inv }} / \partial G_{r c t}$. The maximally possible generation from new renewable energy sources (wind and solar energy) depends on the available natural resource at the geographical position of the installation. Between countries and also within their territory, natural resource quality varies considerably which needs to be taken into account when calibrating the marginal investment cost curves for RE technologies. We assume that in each region the best suited sites for RE generation will be used first and with increasing cumulative installed capacity site quality of new installations deteriorates. ${ }^{11}$ We capture this characteristic by choosing a linear functional form for the marginal investment cost with positive slope:

$$
\frac{\partial \mathcal{C}^{\mathrm{inv}}}{\partial G_{r c}}=c_{r c}^{\mathrm{inv}}+d_{r c}^{\mathrm{inv}}\left(G_{r c}+\bar{r}_{r, c}^{\mathrm{tot}}\right) .
$$

\footnotetext{
9 We require initial and terminal reservoir levels to be equal and thus reservoir net generation capacity is completely determined by seasonal inflows.

${ }^{10}$ We discuss our missing data treatment in greater detail in 6.

11 This is tantamount to saying that the yearly generation in MWh of an additional MW of RE capacity decreases, or that the marginal investment cost per MWh increases with increasing installed capacity.
} 
We derive the intercept, $c_{r c}^{\text {inv }}$, and slope, $d_{r c}^{\text {inv }}$, terms from data on renewable potential provided by Tröndle et al. (2019a, 2019b), proceeding in four main steps. First, for each region in the model, the data (Tröndle et al. 2019a, 2019b) contain estimates for the investment potential for capacity (in MW) and for annual generation (in MWh) on the municipality level. We order the geographical entities in decreasing order by full load hours (i.e., the ratio between annual generation and capacity investment) which gives us the cumulative investment path described above. To this end, each municipality's capacity potential is added to the potential of all the preceding municipalities in this ordering to obtain total installed potential up to the respective point in the list. Second, we calculate cumulative annualized investment cost for each piece of the step function by multiplying the municipality's cumulative capacity potential with the cost per MW for each technology found in the literature (Kost et al. 2018). Third, we divide this cumulative cost by the estimated annual generation in MWh to obtain marginal investment cost per MWh. Fourth, we fit a linear function to the marginal investment cost curve to obtain $c_{r c}^{\text {inv }}$ and $d_{r c}^{\text {inv }}$. Next, we obtain the maximally feasible potential RE generation for each model region in (4), $\pi_{r c}$, by aggregating the generation potentials (Tröndle et al. 2019a) to the country level. ${ }^{12}$

\subsection{Energy Storage}

Electricity storage is modeled on pumped hydro power storage (PHP) in the sense that in the no-policy base case scenario we use the generation capacities, $\bar{k}_{s c}^{J}, \bar{k}_{s c}^{S}, \bar{k}_{s c}^{R}$, and the roundtrip efficiency, $\eta_{s c}$, of this technology in the calibration. The release capacity $\bar{k}_{s c}^{R}$ is given by the net generation capacity for pumped hydro from ENTSO-E (2017) and we set $\bar{k}_{s c}^{J}=\bar{k}_{s c}^{R}$ for the injection (i.e., pumping) capacity. For the storage level capacity, we assume a six hour time frame for complete depletion of the reservoir and set $\bar{k}_{s c}^{S}=6 \times \bar{k}_{s c}^{R}$. The roundtrip efficiency $\eta_{s c}$ is set to $75 \%$, which is found in the literature (Egerer et al. 2014; Newbery 2016). For our computational analysis of flexibility, we take a more general approach to energy storage and relax the capacity constraints, which is equivalent to exogenously adding the necessary amount of storage capacity so that the constraints (7), (8), and (9) are slack. Storage can then be considered generic in the sense that any storage technology has the ability to inject and release electricity into and out of the storage and has a certain degree of efficiency.

\subsection{Demand and Cross-Border Trade Capacities}

Demand $\bar{d}_{c t}$ is modeled to be inelastic and we take its values from ENTSO-E (2017) for all model regions and all of the hours of the year to capture seasonal and intra-day variations in demand. Electricity trade between neighboring model regions is possible where net transfer capacities, $v_{c c^{\prime} t}$, exist. We take net transfer capacities from the Agency for the Cooperation of Energy Regulators (ACER 2018) supplemented by values taken from the Ten Year Network Development Plan 2018 (ENTSO-E 2018) where necessary.

\footnotetext{
12 We adjustment the intercepts $c_{r c}^{\text {inv }}$ where necessary to make sure that investment does not exceed observed levels in the base-year 2017.
} 
Table 3 Flexibility scenarios

\begin{tabular}{llll}
\hline Scenario name & Dimensions of flexibility & & \\
\cline { 2 - 3 } & Regulation & Time & Space \\
& Tradability of green quotas & Energy storage & $\begin{array}{c}\text { Cross- } \\
\text { border } \\
\text { trade }\end{array}$ \\
\hline Constrained \& National quota & National green quotas & $\mathrm{C}^{\mathrm{a}}$ & $\mathrm{C}$ \\
Space \& National quota & & $\mathrm{C}$ & $\mathrm{U}^{\mathrm{b}}$ \\
Time \& National quota & & $\mathrm{U}$ & $\mathrm{U}$ \\
Unconstrained \& National quota & & $\mathrm{U}$ & $\mathrm{C}$ \\
Constrained & Tradable EU green quota & $\mathrm{C}$ & $\mathrm{C}$ \\
Space & & $\mathrm{C}$ & $\mathrm{U}$ \\
Time & & $\mathrm{C}$ & $\mathrm{U}$ \\
Unconstrained & & $\mathrm{U}$ & $\mathrm{U}$ \\
\hline
\end{tabular}

$C$ : constrained. $B$ : unconstrained. ${ }^{\mathrm{a}}$ Capacities as in calibration from input data, ${ }^{\mathrm{b}}$ Capacity limits of the respective dimension (energy storage, cross-border trade) are fully relaxed so that the associated model constraints are slack

\section{Results}

\subsection{Thought Experiments}

Table 3 summarizes the design of our scenario analysis which we use to derive the market impacts and economic cost associated with each of the three flexibility dimensions "Regulation", "Time", and "Space". We analyze temporal flexibility provided by the demand shifting possibilities of energy storage technologies, geographical flexibility due to increased net transfer capacities (NTC) between regions, and regulatory flexibility induced by a more flexible design of RE quotas (which, for example, enables trading obligations to fulfill national RE quotas). We consider two policy specifications: "National green quotas" and "Tradable EU green quota". "National green quotas" is a policy scheme which requires a fixed RE share of final demand in each region while ruling out the possibility of green permit trade between regions. We choose a uniform target of $70 \%$ renewable energy for all the regions covered (i.e., all countries in our data base except for Norway and Switzerland which are not part of the European Union). ${ }^{13}$ In the policy specification "Tradable EU green quota", the policy is designed to achieve the goal of $70 \%$ RE generation in final demand over all EU regions combined (again with the exception of Norway and Switzerland), thus representing a situation where countries may trade green permits so as to equalize marginal investment cost.

For each policy scheme, we investigate four specifications of energy storage capacity and NTC with either both constraints binding at existing capacity levels or both nonbinding or with one of them binding and the other nonbinding. In this way we can go from the most restricted scenario (Constrained \& National quota) to the least constrained scenario

\footnotetext{
13 Our choice of a $70 \%$ target serves to illustrate the case of a very ambitious RE target but is not based on a specific policy proposal. We obtain qualitatively similar results for a $60 \%$ or $80 \%$ target.
} 
Table 4 Percentage change of total cost, sectoral surplus and $\mathrm{CO}_{2}$ emissions relative to the reference scenario

\begin{tabular}{llll}
\hline Scenario & Total cost $\left(\mathcal{C}^{\text {tot }}\right)$ & $\mathrm{W}$ & $\mathrm{CO}_{2}$ emissions \\
\hline Constrained \& National quota & 0.0 & 0.0 & 0.0 \\
Space \& National quota & -7.5 & 6.0 & -42.5 \\
Time \& National quota & -5.2 & 3.1 & -21.3 \\
Unconstrained \& National quota & -8.6 & 6.5 & -39.7 \\
Constrained & -2.5 & 2.3 & 6.2 \\
Space & -13.1 & 11.4 & -46.3 \\
Time & -6.7 & 4.6 & -31.8 \\
Unconstrained & -13.8 & 11.9 & -51.2 \\
\hline
\end{tabular}

The absolute values for the reference scenario are $\mathcal{C}^{\text {tot }}=82.6$ bill. EUR, $|W|=80.8$ bill. EUR, and for 676.3 Mt for $\mathrm{CO}_{2}$ emissions

Unconstrained by systematically increasing flexibility first one channel at a time and then for more than one channel. This allows us to identify the relative impacts of each flexibility dimension.

\subsection{Aggregate Gains at the European (System) Level}

Table 4 shows the impact of increased flexibility on key variables such as total cost, sectoral surplus, and $\mathrm{CO}_{2}$ emissions for all policy scenarios. We focus here on the aggregate level of all regions covered in the model. As our reference, we choose scenario Constrained \& National quota, the scenario with the least flexible system, and percentage changes are calculated with respect to this basis.

Based on the computational analysis with the model, we derive four main insights. First, if the capacities for storage and NTCs are constrained, a more flexible regulatory framework on its own does not create large increases in sectoral surplus. The surplus, $W$, in scenario Constrained is increased by $2.3 \%$ compared to the reference case Constrained \& National quota. A tradable green quota system increases efficiency by allowing participants with high investment cost $^{14}$ to buy permits from those with lower investment cost and thus equalizing marginal investment cost across regions. The remaining physical obstacles, the lack of storage capacity and constrained NTCs, however, prevent further savings because curtailment of RE generation cannot be avoided. It is reduced by $33.8 \%$ in scenario Constrained, which is a considerably smaller reduction than in all other scenarios, where it is close to $100 \%$.

Second, the combination of several flexibility channels is always better than one but the benefits are not simply additive. Not surprisingly, all three flexibility measures applied together yield the highest sectoral surplus in scenario Unconstrained, namely $11.9 \%$. But scenario Space with no further investments into storage capacity and a combination of a permit trading system with no restrictions on NTCs comes very close with a surplus of $11.4 \%$. A combination of unrestricted storage and unrestricted NTCs without tradable

\footnotetext{
${ }^{14}$ Note that investment cost for each country is determined by the geographical potentials for new RE technologies and resource availability profiles.
} 
Table 5 Percentage changes of RE investment and curtailment ${ }^{\mathrm{a}}$ relative to the reference scenario

\begin{tabular}{llllll}
\hline Scenario & \multicolumn{2}{l}{ RE investment } & & \multirow{2}{*}{ Curtailment } \\
\cline { 2 - 5 } & Wind onshore & Wind offshore & Solar & Total & \\
\hline Constrained \& National quota & 0.0 & 0.0 & 0.0 & 0.0 & 0.0 \\
Space \& National quota & -3.8 & -100 & -1.9 & -5.9 & -99.9 \\
Time \& National quota & -25.2 & -100 & 41.4 & -5.9 & -100 \\
Unconstrained \& National quota & -22.1 & -100 & 35.3 & -5.9 & -100 \\
Constrained & 2.8 & -92.2 & -2.5 & -1.5 & -33.8 \\
Space & 11.5 & -100 & -32.8 & -5.9 & -99.8 \\
Time & -17.4 & -100 & 25.8 & -5.9 & -100 \\
Unconstrained & 5.3 & -100 & -20.3 & -5.9 & -100 \\
\hline
\end{tabular}

Percentage changes are measured relative to scenario Constrained \& National quota. ${ }^{\text {a }}$ Curtailment denotes the shedding of excess supply from intermittent RE generation when transmission grid operators deem it necessary to maintain grid stability

green permits fares notably worse with a surplus of $6.5 \%$ in scenario Unconstrained \& National quota, which is only one half percentage point higher than the gains in surplus of unrestricted NTCs alone in scenario Space \& National quota. Taken together, these observations point to the conclusion that flexibility over time periods which is provided by storage on its own is not the most promising flexibility channel if storage losses are nonnegligible and if it is not accompanied by other measures. Given a large and geographically diverse electricity market, geographical flexibility can be more suited to equalize marginal investment cost and marginal generation cost over the entire region.

Third, the new renewable technologies, wind and solar, interact differently with the flexibility channels. Table 5 reports investment into new RE capacities for each scenario. Regardless of geographical position, solar energy is highly concentrated around noon and zero during the night. Therefore, high shares of solar energy in total production are only favorable when storage capacity is high. Solar generation increases compared to the reference scenario Constrained \& National quota when restrictions on storage are lifted and other flexibility channels are not available. In scenario Time \& National quota where storage is the only flexibility improvement, solar investment is up by $41.4 \%$ and wind is down by $25.2 \%$ because every country has to achieve its $70 \%$ RE goal independently and storage favors solar generation. Wind generation patterns are more diverse in different parts of Europe and thus wind has an advantage over solar in scenarios with unrestricted NTCs, especially when also the regulatory framework enables an efficient use of geographical advantages for countries with high resource potentials and allows countries with lower potentials to buy permits.

Fourth, $\mathrm{CO}_{2}$ emissions vary considerably over the different scenarios even though the RE share is constant at $70 \%$. As can be seen from Table 4, emissions in the reference scenario Constrained \& National quota $(188.2 \mathrm{Mt})$ are more than double the emissions in scenario Unconstrained while emissions for scenario Constrained go actually up with the introduction of regulatory flexibility as a single measure. ${ }^{15}$ The emissions reduction

\footnotetext{
${ }^{15}$ Compared to a no-policy case with no further RE investment where $\mathrm{CO}_{2}$ emissions are $676.3 \mathrm{Mt}$, all scenarios constitute a strong reduction in emissions ranging from $70.4 \%$ to $86.4 \%$.
} 


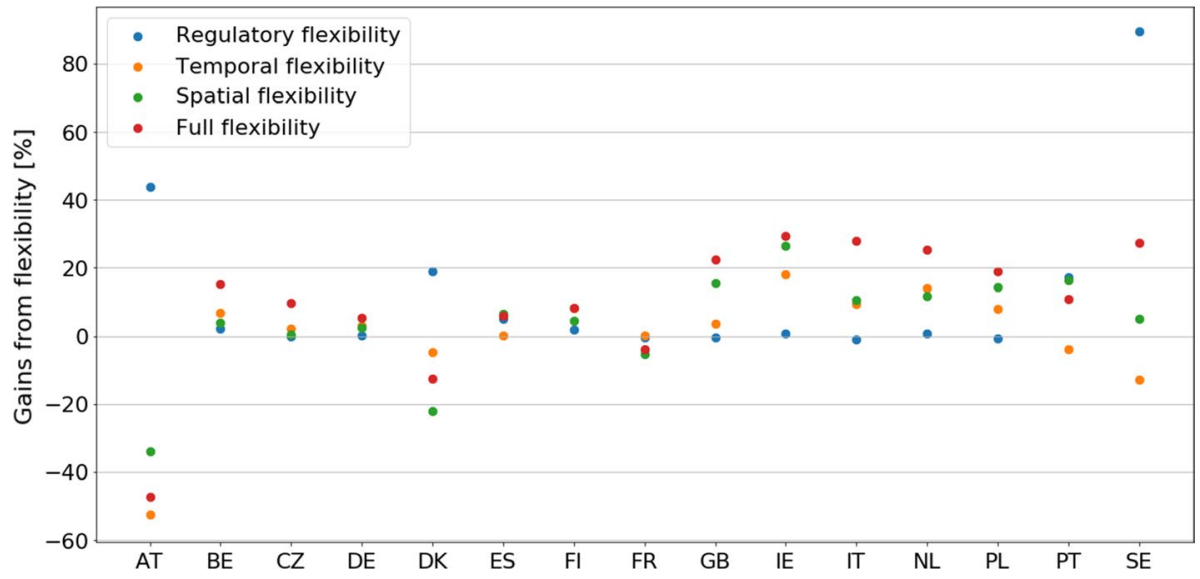

Fig. 4 Gains and losses from added flexibility by European country. Percentage change of sectoral surplus $W$ compared to the reference scenario Constrained \& National quota based on model simulations, where regulatory, temporal, spatial, and full flexibility refer to scenarios Constrained, Time \& National quota, Space \& National quota, and Unconstrained, respectively. Country codes are explained in Table 6

depends on the structure of the conventional generation sectors in the different countries and their interaction.

Increased storage capacity favors base load producers in each country and disadvantages peak load producers. As a consequence, there is a shift in production to each country's lowcost technologies. Since many European countries have coal or nuclear energy as cheap base load technologies, the impact on emissions from storage may either be positive or negative in a given country. The effect of unconstrained trade capacity is different in that it creates a single supply curve for the whole model region and in such a scenario the absolutely cheapest technologies are dispatched first rather than the relatively cheapest production capacity in each country. This favors nuclear and hydro installations over coal and causes larger emissions reductions compared to the scenarios with unconstrained storage.

Lastly, the increase in emissions in scenario Constrained stems from the fact that countries with high marginal investment cost for renewables will buy tradable green permits from other countries and increase production from cheap but dirty fossil capacity compared to the reference scenario Constrained \& National quota where an ambitious target has to be met in each country separately.

\subsection{Gains and Losses by Country}

Figure 4 shows the percentage change of the surplus $W$ for the countries covered in this study $^{16}$, comparing the three scenarios where one of the three flexibility channels is introduced to the case of full flexibility, i.e. a combination of all the three channels. Three main insights emerge with respect to the impacts by country caused by enhancing flexibility.

First, positive percentage gains are not evenly distributed over all countries. Some profit considerably whereas others witness only small improvements. This is mainly due to the

\footnotetext{
${ }_{16}$ We omit Switzerland and Norway, which are not part of the EU and are not bound to the 70\% RE target, and Luxembourg, due to its small market size.
} 
Table 6 Definition of country codes

\begin{tabular}{ll}
\hline Country codes & Countries \\
\hline AT & Austria \\
BE & Belgium \\
CH & Switzerland \\
CZ & Czech Republic \\
DE & Germany \\
DK & Denmark \\
ES & Spain \\
FI & Finland \\
FR & France \\
GB & United Kingdom \\
IE & Ireland \\
IT & Italy \\
LU & Luxembourg \\
NL & Netherlands \\
NO & Norway \\
PL & Poland \\
PT & Portugal \\
SE & Sweden \\
\hline
\end{tabular}

diverse RE potentials and existing conventional capacity mixes which translate into different potentials for cost savings. Second, some countries see absolute losses compared to the least flexible scenario. This is the case when cost savings do not make up for losses in congestion rent, gains from trade, and storage profits due to the increased overall efficiency of the system in its entirety. Examples include countries such as Austria and Denmark. Third, for some countries, more flexibility is not better in terms of sectoral surplus. Again, Austria and Denmark but also Sweden are among the examples. In less flexible scenarios these countries profit from their inflexible neighbors by providing storage services or exports of electricity or green permits. In a highly flexible system, these profits vanish and are not compensated by efficiency gains in the domestic system.

While most countries gain from adding the various flexibility options, our analysis suggests that the gains from increased flexibility are, at least, unevenly distributed; some countries are even worse off. This suggests that the large-scale integration of intermittent renewables in a highly integrated transnational electricity system may require compensating measures at the European level to overcome political hurdles. While it is beyond the scope of this paper to offer an analysis of this question, it is nevertheless important to be aware that designing a more efficient system on an aggregated level does not necessarily guarantee that there are only (country) winners.

\section{Conclusion}

This paper provides an analysis of combining options for increased regulatory, spatial, and temporal flexibility in the European electricity system against the background of integrating large amounts of volatile renewable energy sources in a unified economic market framework. Our analysis aims to better understand the different mechanisms governing the 
Table 7 Fuel prices for conventional technologies

\begin{tabular}{lllll}
\hline & \multicolumn{2}{l}{ Technologies } & & \\
\cline { 2 - 5 } & Hard coal & Lignite & Oil & Gas \\
\hline AT & - & - & - & - \\
BE & - & - & GB & AT \\
CH & - & - & - & - \\
CZ & PL & DE & - & PL \\
DE & - & - & AT & AT \\
DK & DE & - & AT & AT \\
ES & PT & DE & GB & PT \\
FI & - & - & GB & - \\
FR & DE & - & GB & AT \\
GB & - & - & - & - \\
IE & GB & - & GB & GB \\
IT & AT & - & GB & AT \\
LU & - & - & - & AT \\
NL & DE & - & - & AT \\
NO & - & - & - & GB \\
PL & - & DE & AT & - \\
PT & - & - & GB & - \\
SE & FI & - & GB & FI \\
\hline
\end{tabular}

The fuel prices for technology $i$ in country $c$ in the left column, $c_{i c t}^{\mathrm{f}}$, are taken from data for the country indicated in the columns below the technologies. A dash indicates that data for this country and technology were available. Country codes are defined in Table 6

interaction of flexibility options with the existing electricity system and with each other. Our findings emphasize that in the context of RE market integration, it is vital to consider all the relevant system components and market feedbacks. The results of such a broad analysis are needed for a regulator to efficiently manage the transition to a RE dominated complex new electricity system and to help bolster social acceptance of RE support policies and other measures to facilitate RE integration by emphasizing their potential benefits.

Our results show that a suitable combination of flexibility measures such as regulatory flexibility with spatial flexibility will be superior to stand-alone approaches and increase the potential gains in sectoral surplus. Moreover, the impact of policy design and flexibility channels used on emissions reduction depends crucially on the technology mix and capacities of the existing conventional technologies. At the same time, the potential welfare gains and losses of such policies are unevenly distributed among sub-regions or countries within an integrated electricity system, and equity considerations must be taken into account in the design of renewable energy support policies - otherwise the political feasibility of farreaching system transformations required for deep decarbonization is at risk. 
Table 8 Variable O\&M cost for conventional technologies

\begin{tabular}{lllll}
\hline & Technologies & & & \\
\cline { 2 - 5 } & Hard coal & Lignite & Gas & Nuclear \\
\hline AT & DE & - & DE & - \\
BE & - & - & - & - \\
CH & - & - & - & FR \\
CZ & DE & DE & DE & FR \\
DE & - & - & - & FR \\
DK & DE & - & DE & - \\
ES & DE & DE & DE & FR \\
FI & DE & - & DE & - \\
FR & DE & - & - & - \\
GB & NL & - & - & - \\
IE & NL & - & GB & - \\
IT & DE & - & FR & - \\
LU & - & - & DE & - \\
NL & - & - & - & BE \\
NO & - & - & DE & - \\
PL & DE & DE & DE & - \\
PT & - & - & - & - \\
SE & DE & - & DE & FR \\
\hline
\end{tabular}

The variable O\&M costs for technology $i$ in country $c$ in the left column, $c_{i c t}^{\mathrm{O} \& \mathrm{M}}$, are taken from data for the country indicated in the columns below the technologies. A dash indicates that data for this country and technology were available. Country codes are explained in Table 6

\section{Additional Tables and Figures}

Our numerical approach covers 18 European countries and 13 generation and storage technologies. For the empirical assessment the model needs to be calibrated to observed values. However, we do not observe data for all countries and technologies and therefore need to deal with missing data for fuel prices (Table 7), variable O\&M cost (Table 8), and RE production profiles (Table 9). As much as possible, the imputation of missing values relies on geographic proximity, that is we impute missing values from one of the neighboring countries.

Table 7 provides information on the missing data imputation for fuel prices. Hard coal, natural gas, and oil markets are rather integrated, that is price differences across European countries should not be too large. In addition, oil is a peak technology with a rather small installed capacity. Thus, it is rarely active in the base case and driven out of the market with increasing flexibility. Lignite is sold on local markets or often even integrated with electricity generation. Therefore, prices are difficult to obtain. Imputing the German price for Poland, the Czech Republic, and Spain, we likely overestimate prices in these countries due to lower labor cost. Overestimating prices could affect our model results in two major ways. First, the cost ordering of technologies and, second, prices change. Concerning the first point, our lignite values preserve the cost ordering 
Table 9 Availability factors for new RE sources

\begin{tabular}{llll}
\hline & \multicolumn{2}{l}{ Technologies } & \\
\cline { 2 - 4 } & Wind Onshore & Wind Offshore & Solar \\
\hline AT & - & - & - \\
BE & - & - & - \\
CH & - & - & - \\
CZ & - & - & - \\
DE & - & - & - \\
DK & - & - & - \\
ES & - & GB & - \\
FI & - & DK & DK \\
FR & - & GB & - \\
GB & - & - & - \\
IE & - & GB & GB \\
IT & - & GB & - \\
LU & BE & - & BE \\
NL & - & - & - \\
NO & - & DK & DK \\
PL & - & DE & DE \\
PT & - & GB & - \\
SE & - & DK & DK \\
\hline
\end{tabular}

The availability factors for technology $r$ in country $c$ in the left column, $\alpha_{r c t}$, are taken from data for the country indicated in the columns below the technologies. A dash indicates that data for this country and technology were available. Country codes are explained in Table 6

of lignite being cheaper than hard-coal but more expensive than nuclear power. Concerning prices, lignite is rarely the marginal technology, i.e. rarely price setting. Moreover, even if it were price setting, we assume constant demand. Overestimating lignite prices also impacts our total cost estimates. However, due to the small share of lignite and due to the fact that lignite is a sub-marginal technology, the impact on cost-differences across scenarios is expected to be small.

For variable $\mathrm{O} \& \mathrm{M}$, differences in labor costs across countries might introduce biases in the imputed values (Table 8). O\&M costs are however a rather small cost component. The introduced bias is therefore not expected to change the cost ordering of technologies or to have a big influence on cost differences across scenarios.

The availability factor of RE controls the amount of annual RE production available in a certain hour. This, however, neither affects investment cost nor annual production potentials which are calibrated separately. Nevertheless, mis-specifying availability factors might affect our results by altering the replacement of conventional technologies (and with that emissions and cost) as well as storage behavior. Imputed values for offshore wind, however, do not influence the results as we do not observe significant investments into offshore wind in the respective countries. For solar power, we do not observe investments for Sweden or Norway. For Ireland and Finland, we observe small investments in the reference case and the constrained case with green certificates. Also 
for Poland investment is observed in some cases but the imputed values from Germany seem to be reasonable given the proximity of these countries.

Funding Open Access funding enabled and organized by Projekt DEAL.

Open Access This article is licensed under a Creative Commons Attribution 4.0 International License, which permits use, sharing, adaptation, distribution and reproduction in any medium or format, as long as you give appropriate credit to the original author(s) and the source, provide a link to the Creative Commons licence, and indicate if changes were made. The images or other third party material in this article are included in the article's Creative Commons licence, unless indicated otherwise in a credit line to the material. If material is not included in the article's Creative Commons licence and your intended use is not permitted by statutory regulation or exceeds the permitted use, you will need to obtain permission directly from the copyright holder. To view a copy of this licence, visit http://creativecommons.org/licenses/by/4.0/.

\section{References}

Abrell J, Rausch S, Streitberger C (2019) Buffering volatility: storage investments and technology-specific renewable energy support. Energy Econ 84:104463

Abrell J, Rausch S, Streitberger C (2019) The economics of renewable energy support. J Public Econ 176:94-117

ACER (2018) ACER/CEER - Annual Report on the Results of Monitoring the Internal Electricity and Natural Gas Markets in 2017 - Electricity Wholesale Markets Volume. Agency for the Cooperation of Energy Regulators

Antweiler W (2016) Cross-border trade in electricity. J Int Econ 101:42-51

Carson Richard T, Kevin N (2013) The private and social economics of bulk electricity storage. J Environ Econ Manag 66(3):404-423

Claude C, Michel M (2010) Pumped storage and cost saving. Energy Econ 32(2):325-333

Egerer Jonas, Gerbaulet Clemens, Ihlenburg Richard, Kunz Friedrich, Reinhard Benjamin, von Hirschhausen Christian, Weber Alexander, Weibezahn Jens (2014) "Electricity Sector Data for Policy-Relevant Modeling: Data Documentation and Applications to the German and European Electricity Markets." DIW Berlin, German Institute for Economic Research Data Documentation 72. https:// EconPapers.repec.org/RePEc:diw:diwddc:dd72

ENTSO-E (2017). Hourly electricity consumption

ENTSO-E (2017) Hourly electricity generation per production type

ENTSO-E (2017) Net generation capacities

ENTSO-E (2018) Ten Year Network Development Plan 2018

European Commission (2009) Directive 2009/28/EC of the European Parliament and of the Council of 23 April 2009 on the promotion of the use of energy from renewable sources and amending and subsequently repealing Directives 2001/77/EC and 2003/30/EC

European Commission (2011) Communication from the commission to the European parliament, the council, the European economic and social committee and the committee of the regions energy Roadmap $2050 / * \mathrm{COM} / 2011 / 0885$ final $* /$

European Commission (2018) Directive (EU) 2018/2001 of the European Parliament and of the Council of 11 December 2018 on the promotion of the use of energy from renewable sources

Harrison F, Joshua L (2013) Renewable electricity policies, heterogeneity, and cost effectiveness. J Environ Econ Manag 66:688-707

Helm C, Mier M (2018) Subsidising renewables but taxing storage? Second-best policies with imperfect carbon pricing. Oldenburg Discussion Papers in Economics, No. V-413-18

International Energy Agency (2018) CO2 Emissions from Fuel Combustion 2018

International Energy Agency (2019) Energy Prices and Taxes, Vol 2018 Issue 4

Jan A, Sebastian R (2016) Cross-country electricity trade, renewable energy and European transmission infrastructure policy. J Environ Econ Manag 79:87-113

Jan A, Mirjam K, Sebastian R (2019) Carbon abatement with renewables: evaluating wind and solar subsidies in Germany and Spain. J Public Econ 169:172-202

Kost C, Shammugam S, Jülich V, Nguyen HT, Schlegl T (2018) Levelized cost of electricity. Renewable energy technologies. Fraunhofer Institute for Solar Energy Systems (ISE). https://www.ise.fraunhofer. de/en/publications/studies/cost-of-electricity.html 
Linn J, Shih JS (2016) Does electricity storage innovation reduce greenhouse gas emissions? resources for the future resources for the future discussion paper pp. 16-37

Newbery D (2016) A simple introduction to the economics of storage: shifting demand and supply over time and space. EPRG Working Paper, 1626

Nuclear Energy Agency, International Energy Agency, OECD (2015) Projected Costs of Generating Electricity 2015

Rogelj J, Shindell D, Jiang K, Fifita S, Forster P, Ginzburg V, Handa C, Kheshgi H, Kobayashi S, Kriegler E, Mundaca L, Seferian R, Vilarino MV, Calvin K, Edelenbosch O, Emmerling J, Fuss S, Gasser T, Gillet N, He C, Hertwich E, Isaksson L Höglund, Huppmann D, Luderer G, Markandya A, McCollum D, Millar R, Meinshausen M, Popp A, Pereira J, Purohit P, Riahi K, Ribes A, Saunders H, Schadel C, Smith C, Smith P, Trutnevyte E, Xiu Y, Zickfeld K, Zhou W (2018) Chapter 2: itigation pathways compatible with 1.5 ? $\mathrm{C}$ in the context of sustainable development. In: Global Warming of 1.5 ?C an IPCC special report on the impacts of global warming of 1.5 ?C above pre-industrial levels and related global greenhouse gas emission pathways, in the context of strengthening the global response to the threat of climate change. Intergovernmental Panel on Climate Change

Schill WP (2014) Residual load, renewable surplus generation and storage requirements in Germany. Energy Policy 73:65-79

Schill WP, Zerrahn A (2018) Long-run power storage requirements for high shares of renewables: results and sensitivities. Renew Sustain Energy Rev 83:156-171

Sinn H-W (2017) Buffering volatility: a study on the limits of Germany's energy revolution. Eur Econ Rev 99:130-150

Tröndle T, Stefan P, Johan L (2019a) Home-made or imported: on the possibility for renewable electricity autarky on all scales in Europe. Energy Strategy Rev 26:100388

Tröndle T, Pfenninger Stefan, Lilliestam Johan (2019b) Result data related to Tröndle et al (2019) - Homemade or imported: on the possibility for renewable electricity autarky on all scales in Europe

von der Fehr NHM, Lise S (1997) Water on fire: gains from electricity trade. Scandinavian J Econ 99(2):281-297

Wichsinee W (2016) Optimal environmental policies and renewable energy investment: evidence from the Texas electricity market. Clim Change Econ 7(4):1650010

Williams James H, Andrew D, Rebecca G, Amber M, Jack M, Morrow William R, Snuller P, Torn Margaret S (2012) The technology path to deep greenhouse gas emissions cuts by 2050: the pivotal role of electricity. Science 335(6064):53-59

Zerrahn A, Schill WP (2017) Long-run power storage requirements for high shares of renewables: review and a new model. Renew Sustain Energy Rev 79:1518-1534

Zerrahn A, Schill WP, Kemfert C (2018) On the economics of electrical storage for variable renewable energy sources. Eur Econ Rev 108:259-279

Publisher's Note Springer Nature remains neutral with regard to jurisdictional claims in published maps and institutional affiliations. 